\title{
Arugula Seed Powder
}

National Cancer Institute

\section{Source}

National Cancer Institute. Arugula Seed Powder. NCI Thesaurus. Code 1131020.

A dietary supplement containing an extract powder derived from the seeds of the cruciferous vegetable arugula (Eruca sativa), with potential chemopreventive and antioxidant activities. Arugula seed powder contains numerous vitamins and minerals, and is rich in phytonutrients, such as sulforaphane and indole-3-carbinol. Although the exact mechanism of action through which arugula seed powder may exert its anti-tumor effect has yet to be fully elucidated, the effects of this powder on cancer cells may be attributable to the antioxidant and pro-apoptotic activities of the phytonutrients. 